\title{
Oral talampicillin in the treatment of gonorrhoea
}

\author{
J. D. PRICE, J. L. FLUKER, AND A. J. H. GILES \\ From the West London Hospital, London
}

SUMMARY Talampicillin was effective in eradicating the causitive organism in uncomplicated gonorrhoea, with only four treatment failures $(1.6 \%)$ in 245 patients seen at least once after treatment. Symptoms, such as discharge, were seen in 61 patients at some stage after treatment but 31 of these cases were clear after one or two follow-up visits. The antibiotic was well tolerated. One patient developed a maculopapular rash, penicillin allergy was reported in two patients, and a generalised itch (possibly penicillin allergy) in one further patient. A total of 241 out of 245 (98\%) cases had the urethral gonococcus successfully eradicated with talampicillin. Talampicillin given in single doses appears to be an extremely good choice of antibiotic in the treatment of uncomplicated gonorrhoea in men.

\section{Introduction}

The use of single dose antibiotic therapy for the treatment of acute uncomplicated gonorrhoea has been the subject of previous research (Kvale et al., 1971; Masterton and Schofield, 1972; Willcox et al., 1973). This type of treatment results in the eradication of the gonococcus in $98 \%$ of cases in both sexes (Gundersen et al., 1969; Kvale et al., 1971).

For many years after its introduction, penicillin $\mathbf{G}$ was the treatment of choice in gonorrhoea. In 1961, with the advent of ampicillin, a valuable oral therapy was introduced. This semi-synthetic penicillin has now become recognised worldwide as standard oral treatment and single dose administration is recommended by the Venereal Disease Control Division, Center for Disease Control, Atlanta, USA (Center for Disease Control, 1972, 1974) and also by the clinics in the United Kingdom, where it is often given with probenecid (Willcox et al., 1973).

Talampicillin hydrochloride (Talpen) is a derivative of ampicillin which, being an ester of 6 -amino penicillanic acid, is rapidly absorbed from the gastrointestinal tract and is immediately hydrolysed in the mucosa and the blood to ampicillin and the ester moeity. This results in high serum concentrations of ampicillin relative to a comparable dose of ampicillin. As the eradication of the gonococcus from the urethra is related to the tissue level of ampicillin and the length of time that this is maintained, it was decided to undertake a clinical trial with talampicillin using a single dose of $1.48 \mathrm{~g}$ talampicillin, equivalent to $1 \mathrm{~g}$ ampicillin pure free

Address for reprints: Dr J. D. Price, Head of Medical Department, Glaxo Holdings, Graham Street, London N1 8JZ

Received for publication 8 August 1975 acid, plus $1 \mathrm{~g}$ probenecid. The talampicillin was administered in $370 \mathrm{mg}$ gelatine capsules.

\section{Method}

Men attending the West London Hospital with urethral gonorrhoea diagnosed by Gram-stained smear or culture taken at the initial visit were treated with talampicillin. Patients hypersensitive to penicillin or in whom syphilis was suspected were excluded from the study.

A single dose of $1.48 \mathrm{~g}$ talampicillin with $1 \mathrm{~g}$ probenecid was given in the clinic. The patient was instructed to refrain from sexual contact for four weeks and alcohol for two weeks and he was asked to return after three days. Further follow-up was arranged at one, two, and four weeks when further smears and samples for culture were taken. All side effects were noted.

During follow-up treatment failure was defined as reappearance of gonococci on smear or culture in a patient denying sexual contact after treatment. Reinfection was diagnosed when gonococci reappeared on smear or culture and the patient admitted to further sexual contact.

\section{Results}

Two hundred and eighty-seven men suffering from uncomplicated gonorrhoea were treated with talampicillin in this study. Pretreatment microbiological results were as follows: $235(81.9 \%)$ patients had both positive smear and culture results, $42(14.6 \%)$ positive by smear only, and $10(3.5 \%)$ positive by culture only. Two hundred and eighty-five $(99 \cdot 3 \%)$ of the patients complained of symptoms for which 
they sought medical advice. One patient vomited immediately after treatment and is excluded from the assessment.

The findings at follow-up are shown in Tables 1 and 2 . There were only four $(1 \cdot 6 \%)$ treatment failures in the 245 patients seen at least once after treatment. Two patients were regarded as having failed treatment at their first visit on days 8 and 10 . Two were regarded as having failed at their second visit on days 5 and 7.

Table 1 Clinical response (patients bacteriologically cured)

\begin{tabular}{|c|c|c|c|c|c|c|c|}
\hline \multirow[t]{2}{*}{ Follow-up } & \multicolumn{6}{|c|}{ Time (days) after treatment } & \multirow[b]{2}{*}{ Total } \\
\hline & $1-3$ & $4-7$ & $8-14$ & $15-21$ & $22-28$ & $>28$ & \\
\hline \multicolumn{8}{|l|}{ First } \\
\hline clean and dry & 99 & 83 & 25 & 6 & - & - & 243 \\
\hline urethritis & 16 & 9 & 4 & 一 & 1 & - & \\
\hline \multicolumn{8}{|l|}{ Second } \\
\hline clean and dry & 一 & 12 & 79 & 17 & 2 & 11 & 151 \\
\hline urethritis & - & 1 & 20 & 4 & 3 & 2 & \\
\hline \multicolumn{8}{|l|}{ Third } \\
\hline clean and dry & 一 & - & 5 & 19 & 18 & 16 & 63 \\
\hline urethritis & - & - & 3 & 1 & 1 & - & \\
\hline
\end{tabular}

Table 2 Bacteriological response (all patients)

\begin{tabular}{llllll}
\hline Follow-up & -Gonococcus & Fail & $\begin{array}{l}\text { Re- } \\
\text { infection }\end{array}$ & $\begin{array}{l}\text { Un- } \\
\text { assessable }\end{array}$ & $\begin{array}{l}\text { Total } \\
\text { assessable }\end{array}$ \\
\hline 1st & 243 & 2 & 1 & $41^{*}$ & 245 \\
2nd & 151 & 2 & 4 & 130 & 153 \\
3rd & 63 & - & 4 & 220 & 63 \\
\hline
\end{tabular}

*One patient vomited treatment.

\section{Side effects}

A skin reaction occurred in four patients; one developed a maculopapular rash, two demonstrated a true penicillin urticarial reaction, and one had a generalised irritation of the skin without a rash which was attributed to a sensitivity to penicillin. The gonococcus was eradicated within four days in three of these patients, and the fourth was regarded a treatment failure and given spectinomycin.

\section{Discussion}

During the time that this trial was being conducted a temporary suspension of routine sensitivity testing of the gonococcus to penicillin occurred. It is known, however, that there has been no marked change during the past four years in the sensitivities of the gonococci cultured from patients seen in the West London Hospital, approximately $20 \%$ of the organisms being partially insensitive to benzyl penicillin-that is, above 0.03 units $/ \mathrm{ml}$ to 0.1 units $/ \mathrm{ml}-10 \%$ showing a sensitivity from 0.1 to 1.0 units $/ \mathrm{ml}$, and $3 \%$ above this level (Price and Fluker, 1975).

Olsen and Lomholt (1969) reported the results of a single injection of 5 megaunits of benzyl penicillin with $1 \mathrm{~g}$ of probenecid given orally in 832 cases in Greenland and showed that $99 \%$ were cured. Onyeabo, 1970 (personal communication) using $2 \mathrm{~g}$ ampicillin with an injection of 3.6 megaunits procaine penicillin intramuscularly with $2 \mathrm{~g}$ probenecid had four failures $(1.3 \%)$ in 310 women with gonorrhoea. The Center for Disease Control in Atlanta, USA has made recommendations that for the treatment of uncomplicated gonorrhoea $4 \cdot 8$ megaunits of penicillin $\mathrm{G}$ with $1 \mathrm{~g}$ of probenecid is the dose required to treat a gonococcal infection successfully and that for single oral dose therapy for both men and women $3.5 \mathrm{~g}$ of ampicillin with $1 \mathrm{~g}$ of probenecid administered simultaneously should be given (Center for Disease Control, 1974).

Kvale et al. (1971) showed a success rate of $96 \%$ using $3.5 \mathrm{~g}$ of ampicillin in $1 \mathrm{~g}$ probenecid in 202 patients with gonococcal urethritis acquired in the Philippines, and where the same dose of ampicillin without probenecid was used a failure rate of $29.3 \%$ resulted.

It is therefore interesting to see that with the administration of talampicillin, a dose of $1.5 \mathrm{~g}$, equivalent to $1 \mathrm{~g}$ ampicillin, pure free acid is so well absorbed that when used with $1 \mathrm{~g}$ probenecid in men treated for urethral gonorrhoea, the failure rate is only $2 \%$. The advantage of the smaller dose to achieve such a good clinical response rate would be to reduce the incidence of any side effect and development of resistant strains. Further work with this method of administration should be undertaken as it appears to be a very satisfactory method of treatment.

We would like to thank Miss M. M. C. Rees for the statistical evaluation of the results and Mrs $\mathrm{V}$. Igglesden for typing the manuscript.

\footnotetext{
References

Center for Disease Control (1972). Recommended treatment schedules for gonorrhea. Morbid Mortal Weekly Report, 21, 82.

Center for Disease Control (1974). Publication No. (CDC) 75-8195, p.14. Department of Health, Education, and Welfare: USA

Gundersen, T., Odegaard, K., and Gjessing, H. C. (1969). Treatment of gonorrhoea by one oral dose of ampicillin and probenecid combined. British Journal of Venereal Diseases, 45, 235-237.

Kvale, P. A., Keys, T. F., Johnson, D. W., and Holmes, K. K. (1971). Single oral dose ampicillin in probenecid treatment of gonorrhea in the male. Journal of the American Medical Association 215, 1449-1453.

Masterton, G., and Schofield, C. B. S. (1972). Doxycycline HC1 (Vibramycin) as a single dose oral treatment of gonococcal and nonspecific urethritis in men. British Journal of Venereal Diseases, 48, $121-125$.

Olsen, G. A., and Lomholt, G. (1969). Gonorrhoea treated by a combination of probenecid and sodium penicillin G. British Journal of Venereal Diseases, 45, $144-148$.

Price, J. D., and Fluker, J. L. (1975). Amoxycillin in the treatment of gonorrhoea. British Journal of Venereal Diseases, 51, 398-400.

Willcox, R. R., Woodcock, K. R., Latto, D., John, J., Redmond, A., Parker, R. B., Rees, G. D., and Cobbold, R. J. C. (1973). Treatment of gonorrhoea with single oral doses of ampicillin plus probenecid. British Journal of Venereal Diseases, 49, 263-267.
} 